\title{
Alternatif Yakıt Biyogaz Potansiyelinin Model Bir İlçe için Araştırılması
}

\author{
Oğuz Yunus Sarıbıyık ${ }^{1 *}$, Rahman Kılıç² \\ 1* Gümüşhane Üniversitesi, Mühendislik Fakültesi, Genetik ve Biyomühendislik Bölümü, 29100, Gümüşhane, Türkiye (ORCID: 0000-0001-9735-8735), \\ oysaribiyik@gumushane.edu.tr \\ ${ }^{2}$ Gümüşhane Üniversitesi, Şiran Mustafa Beyaz Meslek Yüksekokulu, Bitkisel ve Hayvansal Üretim Bölümü, 29700, Gümüşhane, Türkiye (ORCID: 0000-0002-6649- \\ 1776), toprak.rk@gmail.com
}

(İlk Geliş Tarihi 9 Mart 2021 ve Kabul Tarihi 27 Haziran 2021)

(DOI: $10.31590 /$ ejosat.893481)

\begin{abstract}
ATIF/REFERENCE: Sarıbıyık, O. Y. \& Kılıç, R. (2021). Alternatif Yakıt Biyogaz Potansiyelinin Model Bir İlçe için Araştırılması. Avrupa Bilim ve Teknoloji Dergisi, (25), 192-197.

Öz

Dünya nüfusunun artışı ve teknolojik gelişimler sebebiyle ortaya çıkan gıda ve enerji talebini karşılayabilmek için araştırmalar yoğun şekilde devam etmektedir. Enerji ihtiyacını giderebilmek için arz doğal gaz, kömür, petrol gibi fosil kaynaklı yakıtlardan ya da nükleer kaynaklardan sağlanmaktadır. Fosil kaynakların miktarının sınırlı olması ve oluşturduğu sera gazı etkisi sebebiyle alternatif enerji araştırmaların birçoğu biyodizel, biyogaz, rüzgâr, güneş enerjisi gibi yenilenebilir yakıtlar üzerinde yoğunlaşmıştır. Sera gazı etkisini oluşturan gazlar içerisinde karbondioksit ile birlikte metanojen bakterileri tarafından üretilen metan(bataklık-biyogaz) gazları önemli bir yer tutmaktadır. Uygulanabilirliği, sürdürülebilirliği, düşük üretim maliyeti, sera gazı oluşumunu azaltması ve süreç sonucu elde edilen biyokütlenin organik gübre olarak kullanılabilmesinden dolayı biyogaz üretimi alternatif yakıtlar içerisinde ön plana çıkmaktadır. Bu amaçla, birçok ülkede biyogaz üretimi ve buna bağlı oluşan biyogübrenin tarımda kullanımı artarak devam ederken ülkemizin bu alandaki potansiyelinin yeterince belirlenemediği görülmektedir.

Yapılan bu çalışmada ülkemizin bir ilçesi model olarak incelenerek toplam biyokütle potansiyeli belirlenmiş ve biyokütle potansiyeline bağlı olarak elde edilebilecek biyoenerji miktarı araştırılmıştır. Elde edilen sonuçlar incelendiğinde, model ilçenin biyokütle potansiyelinin ilçenin enerji ihtiyacının üzerinde olduğu ve biyogaz üretimi sonrası oluşacak biyogübrenin kullanımı ile toprak kirliliğine sebep olan inorganik gübre kullanımının azaltılabileceği görülmüştür.
\end{abstract}

Anahtar Kelimeler: Biyogaz, Biyoyakıt, Biyogaz Potansiyeli.

\section{The Investigation of the Alternative Fuel Biogas Potential for Model Town}

\begin{abstract}
The investigations have been intensively continuing for responding of energy and food demand depending on the world population increase and the development of the industrial progression. The energy necessities eliminate by using fossil fuels based sources such as natural gas, coal and petrol. However, the amount of the fossil fuels is limited and they create the green houses gas problems, therefore, many of the researches have been focusing on new sustainable alternative energy sources, such as wind power, biodiesel, biogas, solar and biomass. The methane which is released by the methanogen bacteria is occupy a places in green gases which are carbon dioxide and methane. Biogas as an alternative biofuel has higher impact in alternative fuels because of its applicability, sustainability, low production cost, keep the greenhouse gases in balance and produces bio-fertilizer after digestion processes. In those purposes, the biogas investment and investigation increases for all over the world however the potential of biomass conversion and the examination for bio gas production have paid less concern in our country.

In this study, the potential biomass and the amount of the biogas depending on the biomass potential have been investigated on one of the model town, Şiran in Gümüşhane. According to obtained results, it is seen that the biomass potential and the amount of the biogas production are highly enough for model town for natural gas demand and using bio fertilizer which is produced after digestion of biomass can be decreased by the utilization of the synthetic inorganic fertilizer, causing for soil pollution.
\end{abstract}

Keywords: Biogas, Biofuels, Biogas Potential.

\footnotetext{
*Sorumlu Yazar: oysaribiyik@ gumushane.edu.tr
} 


\section{Giriş}

Enerji tüketim miktarı dünya nüfusunun çoğalması ve sanayideki teknolojik gelişmelere bağlı olarak artırmaktadır. Enerji arzının büyük bir kısmı fosil kökenli kömür, doğal gaz, motorin gibi kaynaklardan sağlandığından oluşan sera gazı etkisi çevresel problemlere sebep olmaktadır (Kalinichenko \& Havrysh, 2019; Sharma et al., 2020; Stolarski et al., 2020). Buna bağlı olarak atmosferdeki fosil kaynaklı karbondioksit artış1 1900 yılında yaklaşık 280 ppm iken günümüzde 409 ppm olarak belirlenmektedir(Lindsey, 2021). Bu artışa bağlı olarak ortaya çıkan sera gazı etkisi sebebiyle küresel ısınma gerçekleşmektedir. Küresel 1sınma; seller, kuraklıklar ve kutuplardaki buzulların erime hızının artması gibi mevsimsel değişimlere bağlı doğal felaketlere sebep olmaktadır. Fosil kaynak tüketimi nedeniyle oluşan küresel ısınmanın alternatif enerjiler kullanılarak azaltılması gerekmektedir. Alternatif ve sürdürülebilir enerji kaynaklarına duyulan ihtiyaçtan dolayı biyodizel, biyogaz, rüzgâr, güneş, dalga, jeotermal enerji ve biyogaz gibi alternatif yakıtlar yoğun şekilde araştırılmaktadır (Patel et al., 2020; Raja \& Wazir, 2017; Ren et al., 2020; Rudreshwar \& Balakrishnan, 2020; Sarıbıyık et al., 2010; Q. L. Y. Zhang et al., 2020; Zhoua et al., 2021). Hammadde miktarı ve ulaşımı, kullanım kolaylığı, üretim süreci sonucu oluşan biyogübre potansiyeli gibi faktörlerden dolayı biyogaz üretimi alternatif yakıtlar içerisinde biraz daha ön plana çıkmaktadır (Cestonaro et al., 2015; Chuanchai \& Ramaraj, 2018; Feiz et al., 2020; Panuccio et al., 2016; Quintanar-Orozco et al., 2018). Biyogaz üretimi doğadaki organik maddelerden ve atıklardan metonajen bakterileri tarafından kendiliğinden gerçekleştirilir ancak oluşan metan gazı karbondioksitle birlikte üretilen sera gazının etkinliğini artırırken hava kirliliğine de sebep olmaktadır (Khalil, 2003; Pochwatka et al., 2020). Araştırmalar eğer dünyadaki metan salınımı son 20 yıldaki gibi devam ederse, metanın küresel ısınmaya etkisinin karbondioksitten 84 kat daha güçlü olacağını belirtmektedir(Chukeaw et al., 2021). Dünyada 6 milyar ton/yıl atık oluşurken kişi başı atık üretimi ise 165-225 kg/yıl olarak hesaplanmaktadır(Ferreira et al., 2019; Pavi et al., 2017; Scarlat et al., 2018; Siddique et al., 2020). Bu atıkların oluşturduğu hava kirliliği ve küresel ısınmaya ek olarak doğaya salınan metan gazının yaklaşık \%59'unun zirai kökenli olduğu tespit edilmiştir(Pochwatka et al., 2020). Organik kökenli atıklardan kontrollü şekilde biyogaz üreterek alternatif enerji miktarını artırmak gerekmektedir. $\mathrm{Bu}$ sebeple, büyükbaş, küçükbaş ve kanatlı hayvan atıklarının yanı sıra alglerden, peynir alt suyundan, dikenli incirden meyve atıklarından, kahve atıkları gibi atıklardan biyogaz üretilmektedir (Battista et al., 2016; Comino et al., 2009; Lanari \& Franci, 1998; Montingelli et al., 2015; Quiroz et al., 2021; Spence et al., 2019; Thompson et al., 2021; Tsigkou et al., 2021). Tüm atıklardan uygun şartlarda biyogaz üretimi yapılmasıyla bunlardan kaynaklanan kötü görünüm, koku giderilerek, bulaşıcı hastalık risklerinin önüne geçilecek ve küresel 1sınma azaltılarak hava kirliliğinin de önüne geçilir (Agency(EPA), 2021; Kalinichenko \& Havrysh, 2019). Bunlara ek olarak, tarım arazilerindeki organik atıklardan biyogaz üretimi ile bu maddelerin anız olarak yakılması engellenerek tarım arazilerindeki ekosistem korunmaktadır. Biyogaz üretimi sonucu elde edilen organik gübreler sentetik gübrelerin yerine kullanılarak toprakta oluşan tuzluluğu azaltacağı için özellikle fosforlu sentetik gübrelerden gelen Kadminyum $(\mathrm{Cd})$ ağır metal kirliliği azaltılmaktadır (Abubaker et al., 2012; Boreka \& Romaniuk, 2020; Huang et al., 2018; Ma et al., 2017; Valentinuzzi et al., 2020). Tarım arazilerinde kullanılan biyogübreler hem toprağın tuzluluk miktarının dengeli kalmasını hem de toprak veriminin organik gübreleme yöntemiyle artırılmasını sağlamaktadır (Siddique et al., 2020).

Dünya genelinde fosil kaynaklı yakıtların oluşturduğu sera gazı etkisine bağlı olarak meydana gelen iklimsel değişiklikler, vahşi sulama ve sentetik gübre kullanımı sebebiyle tuzluluk miktarının artması tarımsal yıllık toplam ürün miktarının düşmesine sebep olmaktadır. Bunlara ek olarak, ülkemizde biyogaz üretimi fosil kaynaklı yapılan yakıt ithalatını azaltacağı için ülke ekonomisine katkı sağlayacaktır. Yapılan araştırmalar neticesinde ülkemizin biyogaz üretim kapasitesinin mevcut duruma göre daha fazla olduğu ancak bu potansiyeli ortaya çıkartacak ve uygulayacak çalışmalarda bir takım eksiklikler olduğu anlaşılmaktadır.

Yapılan bu çalışmada, model ilçe olarak Gümüşhane ili Şiran ilçesi biyogaz üretimine yönelik biyokütle potansiyeli ve bu potansiyele bağlı olarak elde edilebilecek biyogaz miktarı yapılan deneysel çalışmalar genişletilerek ve önceki çalışmalar göz önünde bulundurularak hesaplanmıştır. Elde edilecek biyogaz ile ilçenin gaz tüketiminin ne kadarının karşılanabileceği, biyogaz üretimi sonucunda oluşacak biyogübrenin kullanımı ile sentetik gübre kullanımının azaltılabileceği ve ülke ekonomisine katkıları incelenmiştir. Elde edilen sonuçlara göre, hayvansal ve tarımsal biyokütlelerin kullanılabilmesi sonucu elde edilebilecek biyogaz potansiyelinin ilçenin gaz tüketimini rahatlıkla karşılayabileceği ve biyogaz üretiminden sonra oluşan biyogübrenin kullanımı ile hem tarımsal arazilerin veriminin artırılabileceği hem de tarım topraklarının kirliliğin önüne geçilebileceği görülmüştür.

\section{Materyal ve Metot}

Biyogaz üretimi gerçekleştirilirken hayvansal, evsel ve tarımsal biyokütle kaynakları kullanılabilmektedir. Bu bağlamda deneysel çalışmalarda biyogaz üretimi için 50 litrelik laboratuvar tipi 316 paslanmaz çelik metalden üretilmiş, sızdırmaz, elektrik ısıtıcılı ve mekanik karıştırıcılı (dip süpürmeli) pilot biyoreaktörden elde edilen sonuçlar ve önceki çalışma sonuçları temel alınarak hesaplanmıştır. Reaktörde oluşan gaz miktarı G4ECA doğal gaz ölçüm sayacı ile gaz analizleri ise portatif Geotech G5000 gaz analizörü kullanılarak yapılmıştır. Biyogaz üretiminde elde edilen gazların belirlenmesi için numune alma işlemlerinde Flexfoilplus numune çantası kullanılıp gazlar Agilent(6820) gaz kromatografisi kolon (molesieve 5A $30 \mathrm{~m}$ $\mathrm{x} 0.53 \mathrm{~mm} \times 50 \mu \mathrm{m})$ kullanılarak belirlenmiştir. Biyogaz üretiminde $\% 60$ kaba ve \% 40 yoğunlaştırılmış yemle beslenen 5 yaşında dişi (Simental) büyükbaş hayvanlardan temin edilen biyokütle günlük olarak kullanılmıştır. Deneylerde biyokütle ağırlık ölçümleri (1slak ağırlık biyokütle oluşumundan itibaren 12 saat içerisinde) alınarak yapılmıştır. Fermantasyon $37{ }^{\circ} \mathrm{C}$ 'de 5devir/dk karıştırma hızıyla 30 gün sürede gerçekleştirilmiştir. Fermantasyonda $13 \mathrm{~kg}$ biyokütle ile $13 \mathrm{~kg}$ saf su reaktörde 50 dk/devir ile 5 dk 275 devir/dk ön karıştırma uygulanıp (biyokütle: su oranları 1:1 olacak şekilde) deney seti 3 tekrarlı olarak yapılmıştır. Elde edilen sonuçlara göre $0.5 \mathrm{~m}^{3} /$ ton biyogaz üretilmiştir. Reaktöre ekstra besi ilavesi ve bakteri aşılaması yapılmamıştır. Biyogaz potansiyeli için canlı grubun oluşturduğu biyokütleler ve tarım arazilerinden elde edilen ve biyogaz üretme potansiyeline sahip materyaller Türkiye İstatistik Kurumu (TÜİK) ve model ilçe belediyesi verilerine göre hazırlanmıştır ((TÜİK), 2020). 


\section{Araştırma Sonuçları ve Tartışma}

Biyogaz oluşumunda; metanojen bakterileri (oksijensiz, biyolojik ve mikrobiyal bozunma) süreçlerini kullanarak büyük organik molekülleri uygun şartlarda ve farklı basamaklarda daha küçük moleküller haline getirmektedir (Tablo-1). Görünümü renksiz, yanıcı, ana bileşenleri metan ve karbondioksit olan, eser miktarda hidrojen sülfür, azot, oksijen ve karbon monoksit içeren gübre gazı, bataklık gazı gibi adlarla da bilinen bir gaz karışımıdır ve yanma enerjisi $5200 \mathrm{kcal} / \mathrm{Nm}^{3}$ olarak belirlenmiştir(Ferreira et al., 2019).

Biyogaz üretiminde genel olarak kullanılan organik madde miktarının \%40-60 kadarı biyogaza dönüştürülür (Havrysh et al., 2020). Organik biyokütle içerisinde bulunan karbonhidrat, protein, yağlar, lignin ve selüloz gibi büyük moleküller öncelikle enzimatik basamaklarla daha küçük moleküllere dönüştürülmektedir. $\mathrm{Bu}$ işlem gerçekleştirildikten sonra metanojen bakterileri devreye girerek biyogaz (metan ve karbondioksit) oluşumunu sağlamaktadırlar (Tablo-3) (Xue et al., 2020).

Biyogaz üretiminde kullanılan metanojenik bakteriler; asidogenik, asetat kullanan (asetotrofik) metanojenler ve (hidrojenotrofik) hidrojen kullanan bakteriler olarak üç ayrı grupta incelenirler (Kushkevych et al., 2017). Asidogenik bakteriler tekli alkol bileşikleri oluştururlar ve diğer asetotrofik metanojen bakteriler asetat molekülünü karbondioksit ve metana dönüştürürler. Hidrojen kullanan bakteriler ise elektron kaynağ olarak hidrojeni, karbondioksiti de hidrojen kabul edici olarak metan gazını üretmektedirler. (Şekil-1, Tablo-1)(Yin et al., 2019).

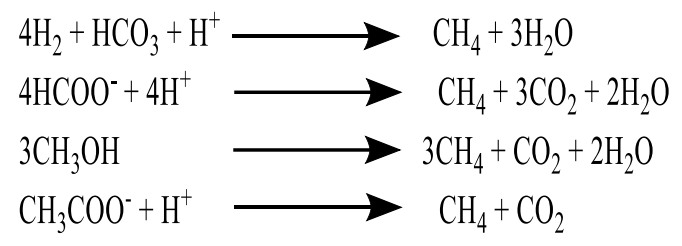

Şekil 1. Biyogaz Oluşum Aşamaları

Tablo 1. Fermantasyona Giren Polimerik Bileşiklerin Metan Gazına Oluşum Döngüsü(Raja \& Wazir, 2017)

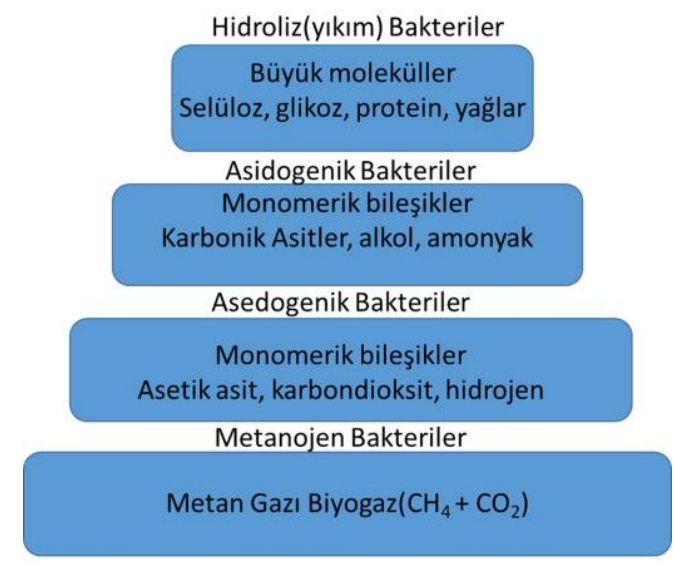

Türkiye mevcut sanayi birikimi, tarım ve hayvancılık potansiyeli incelendiğinde biyogaz gibi alternatif enerjiler açısından zengin kabul edilebilecek yeterli varlığa sahiptir. Diğer dünya devletleri ile kıyaslandığında alternatif enerji üretiminin mevcut potansiyele göre yetersiz kaldığı ancak biyokütleye bağ ${ }_{1}$ biyogaz üretiminin rahatlıkla artırılabileceği görülmektedir.
Yapılan hesaplamalarda Türkiye'de sadece hayvansal biyokütle kaynaklarının biyogaz üretiminde kullanılmasıyla ülkenin 2019 doğal gaz tüketim değerlerine göre yaklaşık \%4'lük kısmının karşılanabileceği görülmektedir. Dünya devletleri 2050 yılı karbon salınımına bağlı sera gazı seviyesini azaltmak için hazırlanan yol haritasına göre alternatif enerji kullanımının yaygınlaştırılması gerekmektedir. Bu sebeple, Çin ve özellikle doğu Avrupa devletleri alternatif enerji kaynakları olarak biyogaz üretimi üzerine yatırımlarını ve araştırmalarını artırmaktadır (Agency, 2020; Balussou, 2018; Benato \& Macor, 2019; Cucchiella et al., 2019; Eyl-Mazzega \& Mathieu, 2019; Ferreira et al., 2019; Gu et al., 2016; Havrysh et al., 2020; Lukehurst et al., 2010; Meyer et al., 2018; Murray et al., 2014; Niskanen \& Magnusson, 2021; Scarlat et al., 2018; Sif et al., 2014; Winquist et al., 2019; Yin et al., 2019).

Tablo 2. Model İlçe Bitkisel ve Hayvansal Kökenli Atık Biyogaz Miktarı ve Enerji Potansiyeli

\begin{tabular}{|c|c|c|c|}
\hline $\begin{array}{c}\text { Hayvan } \\
\text { Cinsi }\end{array}$ & Hayvan sayısı & $\begin{array}{c}\text { Biyokütle } \\
\text { (ton)/yıl }\end{array}$ & $\begin{array}{c}\text { Biyogaz verimi } \\
\mathrm{m}^{3} / \text { ton }\end{array}$ \\
\hline Büyükbaş & 18.937 & 13.7 & $0.1-260$ \\
\hline Küçükbaş & 8.580 & 0.88 & 58 \\
\hline Kanatlı & 11.630 & 0.047 & 78 \\
\hline Ürün çeşidi & $\begin{array}{c}\text { Ekilen Alan } \\
\text { (da) }\end{array}$ & $\begin{array}{c}\text { Artık miktarları } \\
\text { kg/da }\end{array}$ & $\begin{array}{c}\text { Biyogaz verimi } \\
\mathrm{m}^{3} / \text { ton }\end{array}$ \\
\hline Arpa & 7.149 & 234 & 168 \\
\hline Aspir & 6.400 & 200 & 140 \\
\hline Buğday & 4.800 & 225 & 188 \\
\hline Misır & 45.673 & 9.000 & 451 \\
\hline Yeşil ot* & 30.850 & 5.100 & 140 \\
\hline $\begin{array}{c}\text { Hayvansal/ } \\
\text { Bitkisel } \\
\text { Biyogaz } \\
\end{array}$ & $\begin{array}{l}\text { Biyogaz } \\
\left(\mathrm{m}^{3} / \mathbf{y l}\right)\end{array}$ & $\begin{array}{l}\text { Isıl Değer } \\
\left(\mathbf{G J} / \mathbf{m}^{\mathbf{3}}\right)\end{array}$ & Isıl Değeri (GJ) \\
\hline Hayvansal & 396.284 & \multirow{3}{*}{0,024} & 9.511 \\
\hline Bitkisel & 3.067 .762 & & 73.626 \\
\hline Toplam & 3.464 .046 & & 83.137 \\
\hline
\end{tabular}

*Yeşil ot( korunga, fĭg, yonca vs.)

$\mathrm{Bu}$ bağlamda ülkemizde hazırlanan eylem planları kapsamında alternatif enerjiler için devlet desteklerine bağlı olarak özel sektör yatırımları artmaktadır. Biyogaz üretimi, büyükbaş hayvanlardan elde edilen biyokütle miktarına, biyogaz üretim yöntemine, beslenmeye, reaktör türüne, metanojen bakteri türleri gibi parametrelere bağlı olarak değişiklik göstermektedir (Alfa et al., 2014; Amon et al., 2007; Bassey et al., 2013; Bernard et al., 2020; Hidayati et al., 2019; India, 2021; Li et al., 2020; Malik et al., 2020; Z. Zhang et al., 2016). Bu sebeple, yapılan hesaplamalarda daha önce yapılan çalışmalar incelenip bu çalışmada deneysel elde edilen sonuçların ortalaması (0.5 m³/ton) kullanılmıştır (Abdallah et al., 2018; Alfa et al., 2014; Amon et al., 2007; Association, 2021; Bassey et al., 2013; Bernard et al., 2020; Hasan et al., 2018; Hidayati et al., 2019; India, 2021; Li et al., 2020; Malik et al., 2020; Selvankumar et al., 2017; Yohaness, 2010; Z. Zhang et al., 2016). Enerji hesaplamalarında elde edilen toplam biyogaz içerisindeki arındırılmış biyogaz (upgrade biomethane) miktarı ölçüm sonuçlarına göre elde edilen değerler (\% 65 metan) kullanılarak hesaplanmıştır. Türkiye'nin sadece hayvansal biyokütle potansiyeline bakıldığında, Haziran 2020 TÜİK 
verilerine göre, sığır, koyun-keçi ve tavuk-hindi vb. gibi toplam 295.278.329 hayvandan, yılda yaklaşık olarak 71.772.630 ton yaş gübre elde edilmektedir ((TÜİK), 2020). Bu miktarın alternatif yakıtlara büyük katkı sağlayacak potansiyele sahip olduğu rahatlıkla görülmektedir.

Tablo 3. $\mathrm{CO}_{2}$ Dönüşüm Şemas1

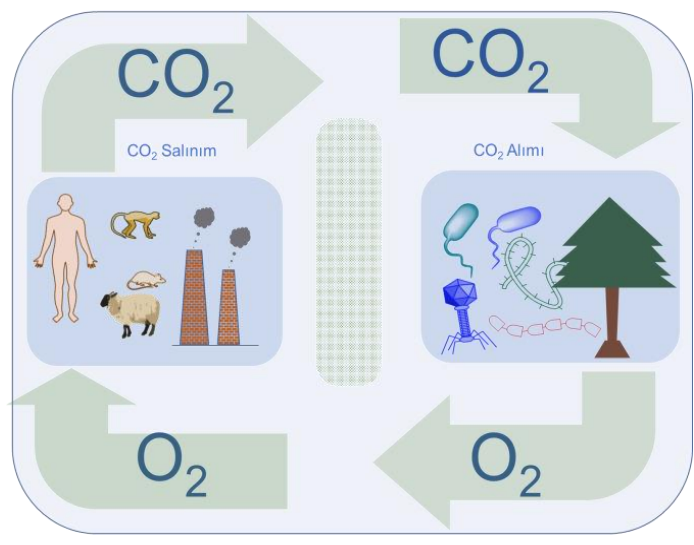

Model ilçenin mevcut biyokütle varlığı incelendiğinde ortaya çıkan bulgulara göre biyokütle potansiyelinin tamamı biyogaz üretim sürecinde kullanılabilirse üretilecek toplam biyogaz miktarı 3.464.046 (m³/yıl) olarak hesaplanmıştır(Tablo-2). İlçenin biyokütle kaynaklı üretilen toplam biyogaz miktarı model ilçenin yaklaşık gaz tüketimiyle 1.429.280 (m³/yıl) kıyaslandığında, hesaplanan yaklaşık teorik değerler olarak üretim miktarı doğal gaz tüketim miktarından daha fazla olduğu görülmektedir. Bu sebeple üretilen biyogazın bir kısmını içten yanmalı motorlarda, taşımada, elektrik üretiminde ve tarım amaçlı kullanılabileceği görülmektedir (Abubaker et al., 2012; Cucchiella et al., 2019; Scholwin et al., 2018). Bu çalışmada, her ne kadar biyogaz potansiyeli araştırılmış olsa da ekonomik değer olarak örneğin Polonya'da yapılan bir çalışmada sadece süt üretilen çiftlikle süt üretiminin yanında biyogaz üretimi de yapılan (600 büyük baş hayvanlı $500 \mathrm{~kW}$ ) çiftlik kıyaslandığında bütün yatırım ve giderler dâhil $€ 332,000 /$ yıl kazançlı olacağı ve yatırım maliyetini 6 yıl içerisinde karşılayacağı görülmektedir (Pochwatka et al., 2020). Bunların dışında, elde edilen sonuçlara göre doğaya kontrolsüz olarak salınan ve sera gazı etkisini artıracak olan $3.464 .046\left(\mathrm{~m}^{3} / \mathrm{y} 1 \mathrm{l}\right)$ metan gazı yakılıp karbondioksite çevrilerek geri dönüşüme kazandırılacaktır (Niskanen \& Magnusson, 2021). Elde edilen verilere göre ülkemizde biyogaz üretimi için potansiyelin mevcut üretimden çok daha yüksek olduğu görülmektedir. Ayrıca biyogaz üretimi sonucu elde edilen organik biyogübrenin özellikleri incelendiğinde, sentetik inorganik gübrelerden kaynaklanan ağır metal kirliliği ve vahşi sulama ile oluşan tuzluluğa bağlı verim düşmesi önlenerek tarımda verim doğal yöntemlerle artırılabilir (Abubaker et al., 2012; Boreka \& Romaniuk, 2020) (Valentinuzzi et al., 2020). Bu çalışmayla alakalı bir diğer çalışmamızın ön sonuçlarına göre biyogübre kullanımıyla bitkilerin tuz stresine karşı direnç geliştirdiği gözlemlenmiştir. Model ilçede biyogaz süreci sonucu elde edilecek yaklaşık biyogübre 14.773 .362 (ton/yıl) böylece tarım topraklarındaki üretim artırılarak hem ülke(ilçe) ekonomisine katkıda bulunur. Şehirlerde oluşan evsel organik atıkların biyogaz üretiminde kullanımıyla vahşi depolama(kötü koku ve görünüm, salgın hastalık, içme suyu bulaş riski, doğal yaşama etkileri vb.) engellenmiş olunur. Böylece katı organik atıkların bertarafı için ekstra maliyet olmaz ve atıklardan enerji üretilmesiyle geri dönüştürülerek ülke ve şehir ekonomisine katkı sağlanır.

\section{Sonuç}

Yapılan çalışma sonucunda elde edilen verilere göre model ilçenin alternatif enerji üretimi için toplam hayvansal ve tarımsal biyokütle kaynakları belirlenmiştir. Deneysel çalışmaların sonuçları da kullanılarak toplam üretilebilecek biyogaz potansiyeline bağlı olarak üretilebilecek elektrik enerjisi yaklaşık olarak 83.137 (GJ) belirlenmiştir. Elde edilen ön verilere göre, ilçenin evsel atıkları göz ardı edilmesine rağmen üretilecek olan biyogazın model ilçenin biyogaz tüketiminden hayli yüksek olduğu görülmektedir. $\mathrm{Bu}$ bilgiler kapsamında yapılan hesaplamalarda; model ilçenin biyokütle varlığından biyogaz üretilmesi durumunda sadece biyogaz tüketimi için yaklaşı $\quad 6.000 .000 \quad(\mathrm{TL} / \mathrm{y} 1) \quad$ kadar ekonomik katkı sağlanabileceği öngörülmektedir. Bunların dışında, biyogaz üretimi gerçekleştikten sonra oluşan biyogübre kaynaklarının yaklaşık 14.773 .362 (ton/yıl) olduğu ve bölgede kullanılan toplam inorganik kökenli sentetik gübrelere karş1lık yeterli miktarda olabileceği görülmektedir. Biyogaz üretiminden elde edilecek organik gübrenin tarımda kullanılması ile vahşi sulamaya bağlı oluşan tuzluluk stresi azaltılacak ve sentetik gübre kullanımına bağlı ağır metal kirliliğinin önüne geçilebilecektir ve çiftçilerin gübre maliyeti düşürülmüş olacaktır. Sonuçta, biyokütle kaynakları kullanılarak; maliyetsiz atık bertarafı sağlanacak, enerji alanında ithalat azaltılarak ekonomik katkı sağlanabilecek ve oluşan biyogübre ile tarım topraklarının ve soluduğumuz havanın daha sağlıklı kalabilmesi sağlanacaktır.

\section{Kaynakça}

Türkiye İstatistik Kurumu (TÜİK), T. (2020). Hayvansal Üretim İstatistikleri. TÜIK, 33874.

Abdallah, M., Shanableh, A., Adghim, M., Ghenai, C., \& Saad, S. (2018). Biogas Production from Different Types of Cow Manure. Advances in Science and Engineering Technology International Conferences doi:10.1109/ICASET.2018.8376791

Abubaker, J., Risberg, K., \& Pell, M. (2012). Biogas residues as fertilisers - Effects on wheat growth and soil microbial activities. Applied energy, doi:http://dx.doi.org/10.1016/j.apenergy.2012.04.050

Agency, E. (2020). Energy in Sweden 2020 An overview. Retrieved from

Agency(EPA), E. P. (2021). Understanding Global Warming Potentials. Retrieved from https://www.epa.gov/ghgemissions/understanding-globalwarming-potentials\#: :tex $\quad \mathrm{t}=$ Methane $\% 20$ (CH4)\%20is\%20estimated,uses\%20a\%20different\%20value.).

Alfa, I. M., Dahunsi, S. O., Iorhemen, O. T., Okafor, C. C., \& Ajayi, S. A. (2014). Comparative evaluation of biogas production from Poultry droppings, Cow dung and Lemon grass. Bioresource Technology doi:http://dx.doi.org/10.1016/j.biortech.2014.01.108

157.

Amon, T., Amon, B., Kryvoruchko, V., Zollitsch, W., Mayer, K., \& Gruber, L. (2007). Biogas production from maize and dairy cattle manure-Influence of biomass composition on the methane yield. Agriculture, Ecosystems and Environment, 118. doi:doi:10.1016/j.agee.2006.05.007

Association, S. G. (2021). Basic Data on Biogas. Swedish Gas Technology Centre: Basic Data on Biogas.

Balussou, D. (2018). An analysis of current and future electricity production from biogas in Germany. Karlsruher Instituts für Technologie (KIT). 
Bassey, A., James, E., Bassey, A., E., A., \& E., E. M. (2013). Four potentials of biogas yield from cow dung-CD. European Journal of Experimental Biology, 3(3).

Battista, F., Fino, D., \& Mancini, G. (2016). Optimization of biogas production from coffee production waste. Bioresource Technology 200, 884-890. doi:http://dx.doi.org/10.1016/j.biortech.2015.11.020

Benato, A., \& Macor, A. (2019). Italian Biogas Plants: Trend, Subsidies, Cost, Biogas Composition and Engine Emissions. mdpi energy, 12, 979. doi:doi:10.3390/en12060979

Bernard, S. S., Srinivasan, T., Suresh, G., Paul, A. I., Fowzan, K. M., \& Kishore, V. A. (2020). Production of biogas from anaerobic digestion of vegetable waste and cow dung. Materials Today: $\quad$ Proceedings, 33. doi:https://doi.org/10.1016/j.matpr.2020.07.129

Boreka, K., \& Romaniuk, W. (2020). Biogas Installation for Harvesting Energy and Unitlization of Natural Fertilisers. sciendo Agricultural Engineering, 24(1), 1-14. doi:DOI: 10.1515/agriceng-2020-0001

Cestonaro, T., Costa, M. S. S. d. M., Costa, L. A. d. M., Rozatti, M. A. T., Pereira, D. C., Lorin, H. E. F., \& Carneiro, L. J. (2015). The anaerobic co-digestion of sheep bedding and P50\% cattle manure increases biogas production and improves biofertilizer quality. waste management, 46, 612-618. doi:http://dx.doi.org/10.1016/j.wasman.2015.08.040

Chuanchai, A., \& Ramaraj, R. (2018). Sustainability assessment of biogas production from buffalo grass and dung: biogas purification and bio-fertilizer. Springer Biotech, 8(151), 2-11. doi:https://doi.org/10.1007/s13205-018-1170-x

Chukeaw, T., Tiyathaa, W., Jaroenpanona, K., Witoon, T., Kongkachuichay, P., Chareonpanich, M.,Seubsai, A. (2021). Synthesis of value-added hydrocarbons via oxidative coupling of methane over $\mathrm{MnTiO}_{3}-\mathrm{Na}_{2} \mathrm{WO}_{4} / \mathrm{SBA}-15$ catalysts. Process Safety and Environmental Protection, 148, 1110-1122. doi:https://doi.org/10.1016/j.psep.2021.02.030

Comino, E., Rosso, M., \& Riggio, V. (2009). Development of a pilot scale anaerobic digester for biogas production from cow manure and whey mix. Bioresource Technology, 100, 50725078. doi:doi:10.1016/j.biortech.2009.05.059

Cucchiella, F., Dadamo, I., \& Gastaldi, M. (2019). An economic analysis of biogas-biomethane chain from animal residues in Italy. Journal of Cleaner Production 230, 888-897. doi:https://doi.org/10.1016/j.jclepro.2019.05.116

Eyl-Mazzega, M.-A., \& Mathieu, C. (2019). Biogas and Biomethane in Europe: Lessons from Denmark, Germany and Italy. $\quad$ Retrieved from https://www.ifri.org/sites/default/files/atoms/files/mathieu_eylmazzega_biomethane_2019.pdf

Feiz, R., Johansson, M., Lindkvist, E., Moestedt, J., Påledal, S. N., \& Svensson, N. (2020). Key performance indicators for biogas productiondmethodological insights on the life-cycle analysis of biogas production from sourceseparated food waste. Energy, 200, 117462. doi:https://doi.org/10.1016/j.energy.2020.117462

Ferreira, S. F., Buller, L. S., Berni, M., \& Forster-Carneiro, T. (2019). Environmental impact assessment of end-uses of biomethane. Journal of Cleaner Production 230, 613e621. doi:https://doi.org/10.1016/j.jclepro.2019.05.034

Gu, L., Zhang, Y.-X., Wang, J.-Z., Chen, G., \& Battye, H. (2016). Where is the future of China's biogas? Review, forecast, and policy implications. Pet. Sci. Springer, 13, 604-624. doi:DOI 10.1007/s12182-016-0105-6

Hasan, M. A., Putra, Z. A., Bilad, M. R., Sapiaa, N. A. H., Wirzal, M. D. H., \& Tijani, M. M. (2018). Biogas production from chicken food waste and cow manure via multi-stages anaerobic digestion. Proceedings of the 3rd International Conference on Applied Science and Technology (ICAST'18). doi:https://doi.org/10.1063/1.5055413

e-ISSN: 2148-2683
Havrysh, V., Kalinichenko, A., Mentel, G., \& Olejarz, T. (2020). Commercial Biogas Plants: Lessons for Ukraine. mdpi energies, 13, 2668. doi:doi:10.3390/en13102668

Hidayati, S., Utomo, T. P., Suroso, E., \& Maktub, Z. A. (2019). Technical and technology aspect assessment of biogas agroindustry from cow manure: case study on cattle livestock industry in South Lampung District. International Conference on Green Agro-industry and Bioeconomy, 230(1). doi:doi:10.1088/1755-1315/230/1/012072

Huang, Q., Yu, Y., Wan, Y., Wang, Q., Luo, Z., Qiao, Y., Li, H. (2018). Effects of continuous fertilization on bioavailability and fractionation of cadmium in soil and its uptake by rice (Oryza sativa L.). Journal of Environmental Management (215), 13-21. doi:https://doi.org/10.1016/j.jenvman.2018.03.036

India, B. P. i. (2021). Biogas:A Fit Option For Rural Energy. Retrieved from https://web.iitd.ac.in/ vkvijay/files/Biogas\%20technology.pdf

Kalinichenko, A., \& Havrysh, V. (2019). Feasibility study of biogas project development: technology maturity, feedstock, and utilization pathway. Polish Academy of Sciences, 45(1), 68. doi:DOI 10.24425/aep.2019.126423

Khalil, M. A. K. (2003). Atmospheric Methane Its Role in the Global Environment. Agricultural and Forest Meteorology, 126, 125-126. doi:doi:10.1016/j.agrformet.2003.09.004

Kushkevych, I., Vítězová, M., Vítěz, T., \& Bartoš, M. (2017). Production of biogas: relationship between methanogenic and sulfate-reducing microorganisms. De Gruyter, 12, 82-91. doi:DOI 10.1515/biol-2017-0009

Lanari, D., \& Franci, C. (1998). Biogas production from solid wastes removed from fiih farm effluents. Aquatic Living Resources, 11(4), 289-295. doi:https://doi.org/10.1016/S09907440(98)80014-4

Li, L., Xu, J., Wang, H., Liu, X., \& Zhang, D. (2020). Study of the performance of biogas production by mixed fermentation of cow dung, deer manure, and mushroom fungus. Energy $S c i$ Engineering, 8. doi:DOI: 10.1002/ese3.528

Lindsey, R. (2021). Climate Change: Atmospheric Carbon Dioxide. Retrieved from

Lukehurst, C. T., Frost, P., \& Seadi, T. A. (2010). Utilisation of digestate from biogas plants as biofertiliser. IEA.

Ma, Y., Yin, Y., \& Liu, Y. (2017). New insights into co-digestion of activated sludge and food waste: Biogas versus biofertilizer. Bioresource Technology 241, 448-453. doi:http://dx.doi.org/10.1016/j.biortech.2017.05.154

Malik, W., Mohan, C., \& Annachhatre, A. P. (2020). Community based biogas plant utilizing food waste and cow dung. Materials Today: Proceedings 28, 1910-1915. doi:https://doi.org/10.1016/j.matpr.2020.05.312

Meyer, A. K. P., Ehimen, E. A., \& Holm-Nielsen, J. B. (2018). Future European biogas: Animal manure, straw and grass potentials for a sustainable European biogas production. Biomass and Bioenergy 111, 154-164. doi:doi.org/10.1016/j.biombioe.2017.05.013

Montingelli, M. E., Tedesco, S., \& Olabi, A. G. (2015). Biogas production from algal biomass: A review. Renewable and Sustainable Energy Reviews, 43, 961-972. doi:http://dx.doi.org/10.1016/j.rser.2014.11.052

Murray, B. C., Galik, C. S., \& Vegh, T. (2014). An Assessment of Market Potential in a Carbon-Constrained Future. Retrieved from

Niskanen, J., \& Magnusson, D. (2021). Understanding upscaling and stagnation of farm-based biogas production in Sweden through transitional and farming logics. Journal of Cleaner Production, 279, 123235. doi:https://doi.org/10.1016/j.jclepro.2020.123235

Panuccio, M. R., Attina, E., Basile, C., Mallamaci, C., \& Muscolo, A. (2016). Use of Recalcitrant Agriculture Wastes to Produce 196 
Biogas and Feasible Biofertilizer. Waste Biomass Volar, 7, 267. doi:DOI 10.1007/s12649-015-9445-5

Patel, R. P., Nagababu, G., Kumar, S. V. V. A., M., S., \& Kachhwah, S. S. (2020). Wave resource assessment and wave energy exploitation along the Indian coast. Ocean Engineering 217

107834. doi:https://doi.org/10.1016/j.oceaneng.2020.107834

Pavi, S., Kramer, L. E., Gomes, L. P., \& Miranda, L. A. S. (2017). Biogas production from co-digestion of organic fraction of municipal solid waste and fruit and vegetable waste. Bioresource Technology, 228, 362-367. doi:http://dx.doi.org/10.1016/j.biortech.2017.01.003

Pochwatka, P., Kowalczyk-Ju'sko, A., Sołowiej, P., Wawrzyniak, A., \& Dach, J. (2020). Biogas Plant Exploitation in a MiddleSized Dairy Farm in Poland: Energetic and Economic Aspects. Energies, 13, 6058. doi:doi:10.3390/en13226058

Quintanar-Orozco, E. T., Vázquez-Rodríguez, G. A., BeltránHernández, R. I., Lucho-Constantino, C. A., Coronel-Olivares, C., Montiel, S. G., \& Islas-Valdez, S. (2018). Enhancement of the biogas and biofertilizer production from Opuntia heliabravoana Scheinvar. Environmental Science and Pollution Research, 25 , 28403-28412. doi:https://doi.org/10.1007/s11356-018-2845-x

Quiroz, M., Varnero, M. T., Cuevas, J. G., \& Sierra, H. (2021). Cactus pear (Opuntia ficus-indica) in areas with limited rainfall for the production of biogas and biofertilizer. Journal of $\begin{array}{llll}\text { Cleaner } & \text { Production } & 289 & \end{array}$ doi:https://doi.org/10.1016/j.jclepro.2021.125839

Raja, I. A., \& Wazir, S. (2017). Biogas Production: The Fundamental Processes. Universal Journal of Engineering Science, 5(2), 29-37. doi:DOI: 10.13189/ujes.2017.050202

Ren, S., Dou, B., \& Ning, F. (2020). Geothermal energy exploitation from depleted high-temperature gas reservoirs by recycling $\mathrm{CO}_{2}$ : the superiority and existing problems. Geoscience Frontiers, pre proof. doi:https://doi.org/10.1016/j.gsf.2020.08.014

Rudreshwar, K., \& Balakrishnan, B. J. (2020). Mini review on recent progress toward sustainable production of biodiesel from biomass. Materials Today: Proceedings doi:https://doi.org/10.1016/j.matpr.2020.08.444

Sarıbıyı,, O. Y., Özcanlı, M., Serin, H., Serin, S., \& Aydın, K. (2010). Biodiesel Production from Ricinus Communis Oil and Its Blends with Soybean Biodiesel. Strojniški vestnik - Journal of Mechanical Engineering, 56(12), 811-816.

Scarlat, N., Dallemand, J.-F., \& Fahl, F. (2018). Biogas: Developments and perspectives in Europe. Renewable Energy 129, 457-472. doi:https://doi.org/10.1016/j.renene.2018.03.006

Scholwin, F., Grope, J., Clinkscales, A., Boshell, F., Saygin, D., Salgado, A., \& Seleem, A. (2018). Biogas for Road Vehicles Technology Brief. Retrieved from

Selvankumar, T., Sudhakar, C., Selvam, K., Aroulmoji, V., Govindaraju, M., Sivakumar, N., \& Govarthanan, M. (2017). Process optimization of biogas energy production from cow dung with alkali pre-treated coffee pulp. Biotech, 7(254). doi:DOI 10.1007/s13205-017-0884-5

Sharma, S., Kundu, A., Basu, S., Shetti, N. P., \& Aminabhavi, T. M. (2020). Sustainable environmental management and related biofuel technologies. Journal of Environmental Management 273 ,

111096. doi:https://doi.org/10.1016/j.jenvman.2020.111096

Siddique, M. N. I., Khalid, Z. B., \& Ibrahim, M. Z. B. (2020). Effect of additional nutrients on bio-methane production from anaerobic digestion of farming waste: Feasibility \& Fertilizer recovery. Journal of Environmental Chemical Engineering, 8, 103569. doi:https://doi.org/10.1016/j.jece.2019.103569
Sif, B. S., Kofoed-Wiuff, Herrmann, A., Tengbjerg, I., \& Bernard, K. K. (2014). Experiences with biogas in Denmark. Retrieved from

Spence, A., Madrigal, E. B., Patilb, R., \& Fernándeza, Y. B. (2019). Evaluation of anaerobic digestibility of energy crops and agricultural byproducts. Bioresource Technology Reports, 243 250. doi:https://doi.org/10.1016/j.biteb.2018.11.004

Stolarski, M. J., Warminski, K., Krzyzaniak, M., Ziety, E. O., \& Stachowicz, P. (2020). Energy consumption and heating costs for a detached house over a 12-year period e Renewable fuels versus fossil fuels. Energy, 204, 117952. doi:https://doi.org/10.1016/j.energy.2020.117952

Thompson, T. M., Young, B. R., \& Baroutian, S. (2021). Enhancing biogas production from caribbean pelagic Sargassum utilising hydrothermal pretreatment and anaerobic co-digestion with food waste. Chemosphere, 275, 130035. doi:https://doi.org/10.1016/j.chemosphere.2021.130035

Tsigkou, K., Zagklis, D., Tsafrakidou, P., Zapanti, P., Manthos, G., Karamitou, K., Kornaros, M. (2021). Expired food products and used disposable adult nappies mesophilic anaerobic codigestion: Biochemical methane potential, feedstock pretreatment and two-stage system performance. Renewable Energy, 168, 309-318. doi:https://doi.org/10.1016/j.renene.2020.12.062

Valentinuzzi, F., Cavani, L., Porfido, C., Terzano, R., Pii, Y., Cesco, S., Mimmo, T. (2020). The fertilising potential of manure-based biogas fermentation residues: pelleted vs. liquid digestate. Heliyon, 6, e3325. doi:https://doi.org/10.1016/j.heliyon.2020.e03325

Winquist, E., Rikkonen, P., Pyysiainen, J., \& Varho, V. (2019). Is biogas an energy or a sustainability product? - Business opportunities in the Finnish biogas branch. Journal of Cleaner Production 233, 1344-1354. doi:https://doi.org/10.1016/j.jclepro.2019.06.181

Xue, S., Wang, Y., Lyuc, X., Zhao, N., Song, J., Wang, X., \& Yang, G. (2020). Interactive effects of carbohydrate, lipid, protein composition and carbon/ nitrogen ratio on biogas production of different food wastes. Bioresource Technology, 312, 123566. doi:https://doi.org/10.1016/j.biortech.2020.123566

Yin, C., Shen, Y., Yu, Y., Yuan, H., Lou, Z., \& Zhu, N. (2019). Insitu biogas upgrading by a stepwise addition of ash additives: Methanogen adaption and $\mathrm{CO}_{2}$ sequestration. Bioresource Technology, 282, 1-8. doi:https://doi.org/10.1016/j.biortech.2019.02.110

Yohaness, M. T. (2010). Biogas potential from cow manure Influence of diet. (Master), Swedish University, (ISSN 11018151)

Zhang, Q. L. Y., Mieghem, A. V., Chen, Y.-C., Yu, N., Yang, Y., \& Yin, H. (2020). Design and experiment of a sun-powered smart building envelope with automatic control. Energy \& Buildings, 223, 110173. doi:https://doi.org/10.1016/j.enbuild.2020.110173

Zhang, Z., Zhang, G., Li, W., Li, C., \& Xu, G. (2016). Enhanced biogas production from sorghum stem by co-digestion with cow manure. internationa $l j$ ournal of hydrogen energy, 41. doi:http://dx.doi.org/10.1016/j.ijhydene.2016.02.042

Zhoua, B., Or, S. W., Chan, K. W., Duan, H., Wu, Q., Wang, H., \& Meng, Y. (2021). Short-term prediction of wind power and its ramp events based on semisupervised generative adversarial network. Electrical Power and Energy Systems 125, 106411. doi:https://doi.org/10.1016/j.ijepes.2020.106411 